\title{
Carbon Dots and [FeFe] Hydrogenase Biohybrid Assemblies for Efficient Light-Driven Hydrogen Evolution
}

\author{
Kateřina Holá," Mariia V. Pavliuk," Brigitta Németh, Ping Huang, Lukáš Zdražil, Henrik Land, \\ Gustav Berggren,* and Haining Tian*
}

Cite This: ACS Catal. 2020, 10, 9943-9952

Read Online

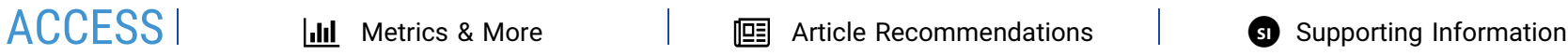

ABSTRACT: Artificial photosynthesis is seen as a path to convert and store solar energy into chemical energy for our society. In this work, highly fluorescent aspartic acid-based carbon dots (CDs) are synthesized and employed as a photosensitizer to drive photocatalytic hydrogen evolution with an $[\mathrm{FeFe}]$ hydrogenase (CrHydA1). The direct interaction in CDs from L-aspartic acid (AspCDs)/CrHydA1 self-assembly systems, which is visualized from native gel electrophoresis, has been systematically investigated to understand the electron-transfer dynamics and its impact on photocatalytic efficiency. The study discloses the significant influence of the electrostatic surrounding generated by sacrificial electron donors on the intimate interplay within the oppositely charged subunits of the biohybrid assembly as well as the overall

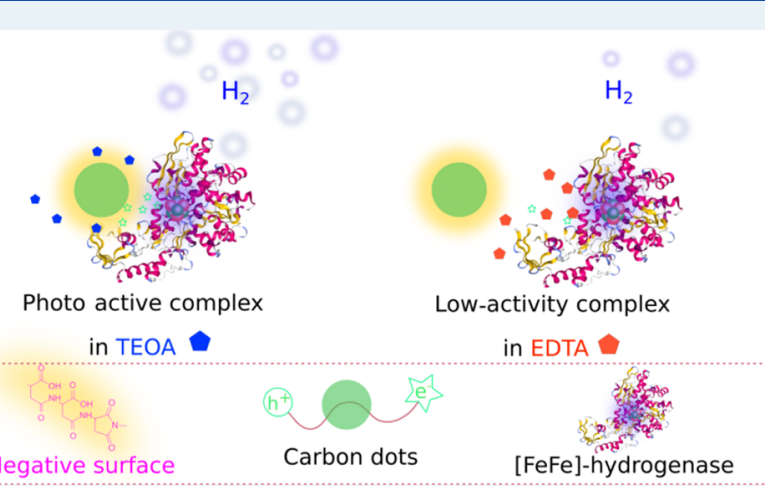
photocatalytic performance. The system reaches an external quantum efficiency of $1.7 \%$ at $420 \mathrm{~nm}$ and an initial activity of 1.73 $\mu \mathrm{mol}\left(\mathrm{H}_{2}\right) \mathrm{mg}^{-1}$ (hydrogenase) $\mathrm{min}^{-1}$ under favorable electrostatic conditions. Owing to the ability of the synthesized AspCDs to operate efficiently under visible light, in contrast to other materials that require UV illumination, the stability of the biohybrid assembly in the presence of a redox mediator extends beyond 1 week.

KEYWORDS: carbon dots, hydrogenase, hydrogen, biocatalysis, artificial photosynthesis

\section{INTRODUCTION}

Artificial photosynthesis is a promising strategy for converting and storing solar energy into clean and sustainable fuels, including hydrogen, methanol, or low-molecular-weight hydrocarbons. Therefore, a great deal of scientific effort has been made in developing scalable eco-friendly systems displaying good conversion efficiencies. ${ }^{2,3}$ Photofuel production requires efficient coupling of the single-electron chemistry of the photosensitizer to the multielectron process of catalysis. ${ }^{4}$ Optimization of this process therefore requires suitable photosensitizers and efficient catalysts as well as a detailed understanding of their interaction(s).

Metal-free light harvesters in contrast to traditional metal oxide semiconductors, ${ }^{5-7}$ quantum dots, ${ }^{8-10}$ and plasmonic photosensitizers $^{11}$ offer low toxicity/low cost. Among potentially interesting photosensitizers are organic molecules/ polymers $^{12-16}$ and carbon-based materials, ${ }^{17}$ for example, carbon nitrides ${ }^{18,19}$ and carbon dots (CDs)/graphene quantum dots. $^{20}$ Great water dispersibility, ${ }^{21-23}$ high photostability, and tunability of absorption above $600 \mathrm{~nm}^{24}$ make CDs stand out among biofriendly photosensitizers for solar fuel production. ${ }^{25-31}$

Nature has provided us with remarkable hydrogen evolution catalysts, the hydrogenase enzymes that catalyze the $\mathrm{H}^{+} / \mathrm{H}_{2}$ interconversion at low overpotentials with rates exceeding $1000 \mathrm{~s}^{-1}$, motivating studies of their biotechnological application. ${ }^{32-34}$ Combining CDs and hydrogenases in order to build biohybrid systems is arguably a promising strategy. ${ }^{20}$ Hydrogenases are large proteins featuring a complex active site buried within the protein matrix and thus require gas channels and pathways for electron and proton shuttling. ${ }^{35-38}$ The engineering of biohybrid assemblies with hydrogenases should consider the following: (i) size compatibility, (ii) availability of preferential binding sites, and (iii) the chemical environment, for example, ionic strength, $\mathrm{pH}$, or charges that influence the interaction between the subunits. To fulfill one of the goals of artificial photosynthesis, namely, charge accumulation, where single-photon/single-electron events are coupled with multielectron reduction reactions, ${ }^{4}$ it is beneficial to have small light-harvesting centers that may consecutively transfer electrons directly to the active site of the hydrogenase, ${ }^{10}$

Received: June 4, 2020

Revised: June 19, 2020

Published: June 22, 2020 
emphasizing the role of size/geometry matching between lightharvesting units with the dimensions of the active site (the pocket) of the hydrogenase. ${ }^{39}$ To even further enhance the interaction between CDs and the active site of the hydrogenase that possesses opposite charges, the electrostatic environment affected by the sacrificial electron donor can play a crucial role. Current approaches for directed binding of redox enzymes include electrostatic/hydrophobic/hydrophilic interactions or specific protein-amino acid bindings. ${ }^{40}$ It has been shown that the electrostatic interaction between the negatively charged ligands of $\mathrm{CdS}$ nanorods and the positively charged binding site of the $[\mathrm{FeFe}]$ hydrogenase enzyme played a crucial role on the preferential site-specific adsorption. ${ }^{41}$ Additionally, Reisner et al. showed that the positive surface charge of CDs affected the electron-transfer efficiency toward the $[\mathrm{NiFe}(\mathrm{Se})]$ hydrogenase enzyme, leading to $48 \mathrm{~h}$ of hydrogen evolution without the presence of a redox mediator. ${ }^{42}$

In the current work, we have studied CDs prepared from Laspartic acid (AspCDs) as a photosensitizer to drive efficient enzymatic catalysis with the artificially maturated [FeFe] hydrogenase from Chlamydomonas reinhardtii (CrHydA1) (Scheme 1). The choice of the biocatalyst is motivated by

Scheme 1. Schematic Representation of the AspCD/ CrHydA1 Biohybrid System for Light-Driven Hydrogen Evolution $^{a}$

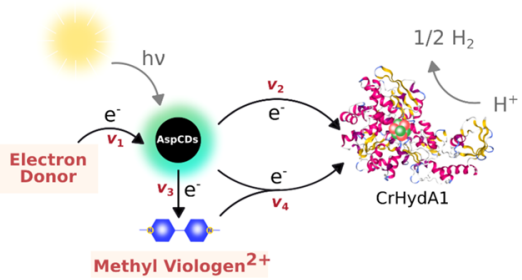

${ }^{a}$ Role of the sacrificial electron donor and methyl viologen (highlighted in red) is discussed in detail as well as the rates of the given electron-transfer steps. the generally higher activities of the $[\mathrm{FeFe}]$ hydrogenase for $\mathrm{H}_{2}$ gas production, as compared to $[\mathrm{NiFe}]$ hydrogenases. The possibility of producing the former enzyme using standard heterologous expression techniques also significantly simplifies the catalyst production. ${ }^{33,34,43}$ We discuss the effect of the sacrificial electron donor on the interaction between the synthesized AspCDs and the $[\mathrm{FeFe}]$ hydrogenase enzyme and its effect on the electron dynamics and photocatalytic performance in the biohybrid assembly.

\section{RESULTS}

Preparation and Characterization of AspCDs. CDs were prepared by solvothermal decomposition of L-aspartic acid at $210{ }^{\circ} \mathrm{C}$ (Figure 1a, more details are provided in the Supporting Information and Figures S1-S4), which renders a water-dispersible product denoted as AspCDs. In contrast to pyrolysis of aspartic acid that operates at temperatures above $300{ }^{\circ} \mathrm{C}$ and requires $\mathrm{NaOH}$ to solubilize the product, the solvothermal method applied here enables solubilization of the reactants at much lower temperatures without the necessity to introduce unnecessary ions, for example, $\mathrm{Na}^{+}$. The AspCDs exhibited fluorescence (Figure 1b) with emission peaks centered at $450 \mathrm{~nm}$ (355 nm excitation) and $525 \mathrm{~nm}$ [420 $\mathrm{nm}$ excitation and a quantum yield (QY) of $21.2 \%]$. The average size of the AspCDs was determined to be $2.5 \pm 1.1 \mathrm{~nm}$ by transmission electron microscopy (TEM, Figure 1c). Moreover, as seen from high-resolution TEM (HR-TEM) images, CDs showed a good degree of graphitization (Figure S5). High-resolution $\mathrm{C} 1 \mathrm{~s} \mathrm{X}$-ray photoelectron spectroscopy (XPS, Figure $1 \mathrm{~d}$ inset, Table $\mathrm{S} 1$ ) revealed that $\mathrm{C}-\mathrm{C} / \mathrm{C}=\mathrm{C}$ and $\mathrm{N} / \mathrm{O}-\mathrm{C}=\mathrm{O}$ bonds were the most dominant peaks (the total composition of the material was carbon $68 \%$, nitrogen $10 \%$, and oxygen $22 \%$ ), reflecting a high amount of carboxylic and amidic functional groups on the surface (Figure 1d).

Among the desired features of photosensitizers, in parallel to the broad visible light absorption, is the ability to efficiently transfer photogenerated charges to the catalyst or a redox mediator. The electron-transfer capabilities of AspCDs were evaluated in the presence of the soluble redox mediator methyl viologen, $\mathrm{MV}^{2+}\left[E^{0 \prime}=-0.43\right.$ vs standard hydrogen electrode

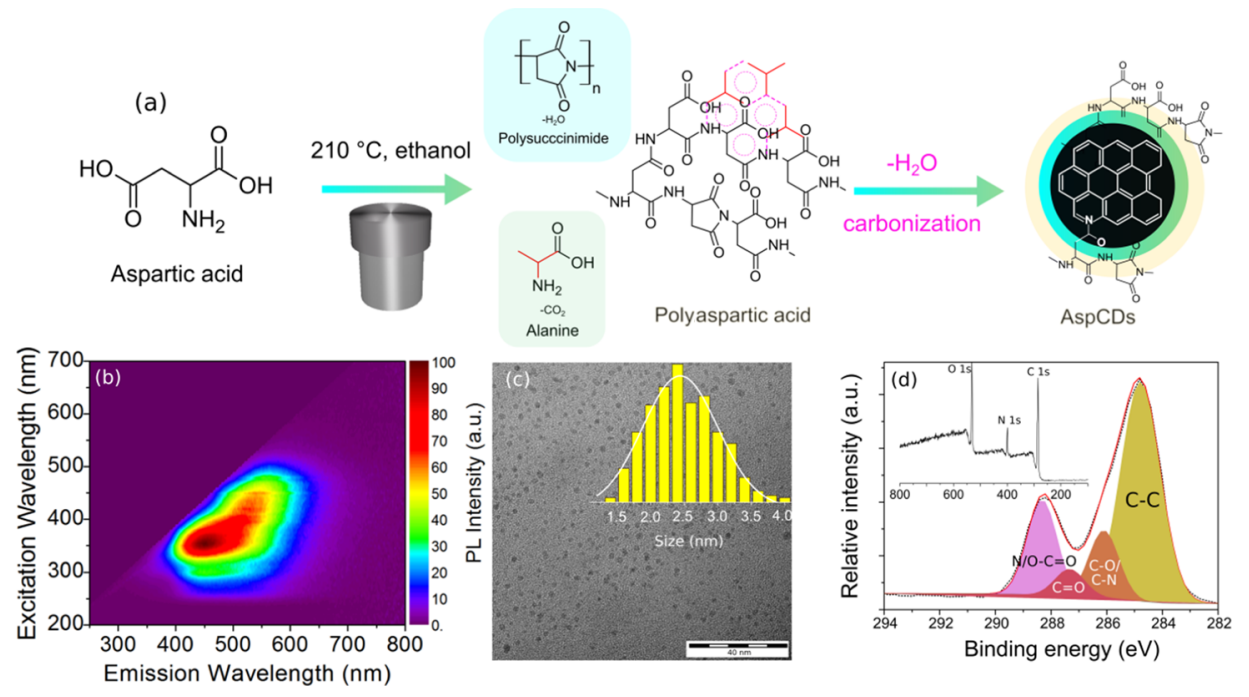

Figure 1. (a) Reaction scheme of AspCD preparation; (b) fluorescent excitation-emission map for prepared AspCDs in water; (c) TEM image of AspCDs with size distribution in the inset, and the scale bar is $40 \mathrm{~nm}$; and (d) survey spectrum (inset) and the high-resolution C 1s XPS spectrum of AspCDs. 
(SHE) at $\mathrm{pH} 7],{ }^{44}$ that provided a favorable reduction potential for hydrogen evolution $\left(E^{0 \prime}=-0.42\right.$ vs SHE at $\mathrm{pH}$ 7). The rise of the characteristic absorption peak of $\mathrm{MV}^{\bullet+}$ (Figure S6) after light illumination in the presence of AspCDs $\left(0.2 \mathrm{mg} \mathrm{mL}^{-1}\right)$ was monitored as a function of time with different sacrificial electron donors under $\mathrm{pH} 4-11$. The photoactivity of AspCDs was negligible at $\mathrm{pH} 4$ (Figure 2) in

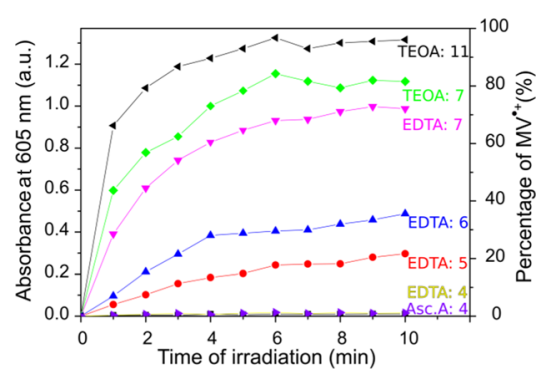

Figure 2. Generation of photoreduced methyl viologen $\left(\mathrm{MV}^{\bullet+}\right)$ after illumination (white LED, $50 \mathrm{~mW} \mathrm{~cm} \mathrm{~cm}^{-2}, 420-700 \mathrm{~nm}$ ) over time monitored by absorption at $605 \mathrm{~nm}$ : the plots are presented for various sacrificial electron donors at different $\mathrm{pH}$ values (concentration of AspCDs: $0.2 \mathrm{mg} \mathrm{mL}^{-1}$, methyl viologen dichloride: $0.1 \mathrm{mM}$, EDTA: $0.1 \mathrm{M}$, TEOA: $10 \%$, and ascorbic acid: $0.2 \mathrm{M}$ ).

the presence of both ascorbic acid $(0.2 \mathrm{M})$ and ethylenediaminetetraacetic acid (EDTA, $0.1 \mathrm{M}$ ). Increasing the $\mathrm{pH}$ from 5 to 11 dramatically improved the reduction rate of $\mathrm{MV}^{2+}$ using EDTA and triethanolamine (TEOA, 10\%, $0.67 \mathrm{M}$ ) as sacrificial electron donors. The fastest rate of $\mathrm{MV}^{\bullet+}$ generation was observed at $\mathrm{pH} 11$. However, as the optimum working condition for CrHydA1 is at $\mathrm{pH} 7,{ }^{45}$ it was decided to perform further investigations in the presence of EDTA and TEOA under $\mathrm{pH} 7$.

The photochemistry of the AspCDs was further analyzed by electron paramagnetic resonance (EPR) spectroscopy. Continuous in situ illumination of the solution of $0.5 \mathrm{mg} \mathrm{mL}^{-1}$ AspCDs containing TEOA ( $\mathrm{pH} 7$ ) under ambient conditions generated an EPR signal centered at $g=2.004$ with a line width of $\sim 5 \mathrm{G}$ (Figure 3a), attributable to an organic radical. No EPR active species was observed in the absence of TEOA (Figure S7a). Switching off the light resulted in an immediate decrease in the intensity of the radical EPR signal, although it took several minutes (ca. 5-10 min) in the dark until complete disappearance of the signal was observed. Similar behavior of the signal was observed in repeated cycles of light on/off.
Thus, the radical signal displayed definite lag behavior in its response upon the transfer from light to dark conditions. Such a shielding effect suggests that the radicals are situated on aggregated particles rather than on single molecules. ${ }^{46}$ Consequently, this $g=2.004$ radical signal is attributed to reduced AspCDs.

The negative surface charge of the prepared AspCD particles (Figure S1) provides a suitable interface for the self-assembly with the $[\mathrm{FeFe}]$ hydrogenase. ${ }^{8,39}$ More specifically, CrHydA1 features as a positively charged pocket on the surface near the active site of this enzyme (Figure 4), providing an ideal
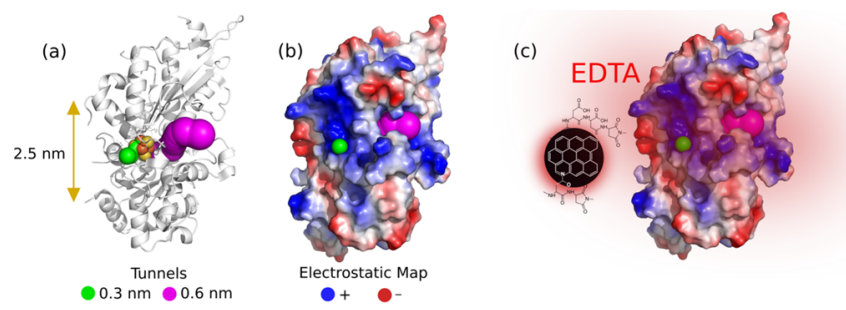

Figure 4. (a) Model of CrHydAl generated from its crystal structure (PDB ID: 3LX4); the calculated channels are labeled in green and violet, and the average size of AspCDs $(2.5 \mathrm{~nm})$ is illustrated with a yellow bar; (b) electrostatic map of $\mathrm{CrHydA1}$; positively charged areas are indicated in blue, negatively charged areas are indicated in red, and the tunnels present are also labeled; and (c) illustration of the weakened interaction of AspCDs with CrHydAl once employing negatively charged EDTA.

docking site for the AspCD particles. ${ }^{8,39,47-49}$ It should be noted that CDs are smaller than the hydrogenase; thus, we cannot exclude that several CDs may associate with one molecule of the hydrogenase, providing a larger number of light-harvesting centers around the catalyst. However, considering the size of the CDs and the positively charged area surrounding the active site of the hydrogenase (see Figure $4 c)$, probably one or at most two CDs are close enough to the active site and dominate the electron-transfer process to the enzyme.

The stability of the enzyme in the AspCDs/CrHydAl assembly was analyzed by EPR spectroscopy, for which samples were prepared at room temperature before they were flash-frozen. The addition of CrHydAl $(10 \mu \mathrm{M})$ to an aqueous solution with $0.5 \mathrm{mg} \mathrm{mL}^{-1}$ AspCDs and TEOA ( $\mathrm{pH}$ 7) resulted in the appearance of two EPR active species. As
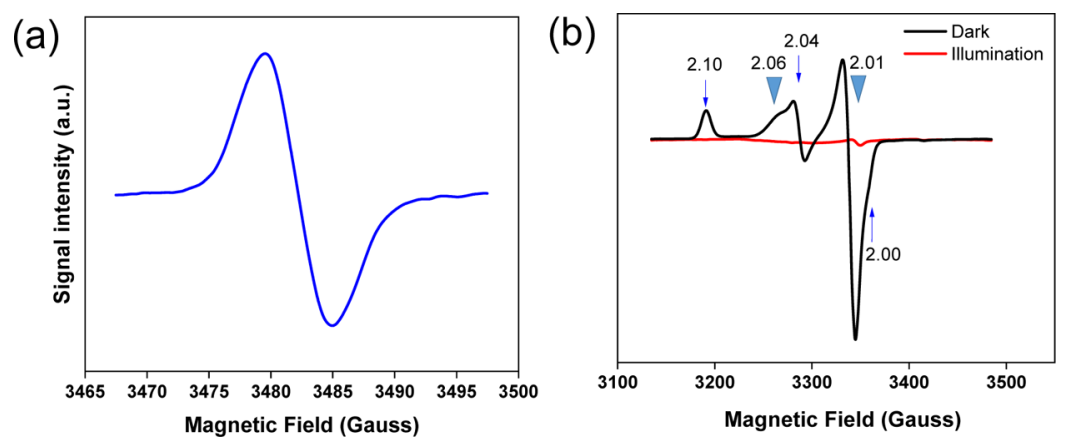

Figure 3. (a) X-band EPR spectrum of the AspCD radical $(g=2.004)$ recorded under in situ continuous light illumination and an ambient atmosphere; (b) EPR spectra recorded at $21 \mathrm{~K}$ of a solution composed of $0.5 \mathrm{mg} \mathrm{mL}{ }^{-1}$ AspCDs, TEOA ( $\mathrm{pH}=7$ ), and $10 \mu \mathrm{M} \mathrm{CrHydA1} \mathrm{before}$ (black) and after (red) light exposure. The EPR features of the as-prepared sample (b, black) are attributed to the $\mathrm{H}_{\mathrm{ox}}$ state $[g=2.10,2.04$, and $2.00(\downarrow)]$ and the $\mathrm{H}_{\mathrm{ox}}-\mathrm{CO}$ state $[g=2.06$ and $2.01(\boldsymbol{\nabla})]$. 
seen in Figure $3 b$, the spectrum featured a rhombic signal that can be assigned to the $\mathrm{H}_{\mathrm{ox}}$ state $(g=2.10,2.06$, and 2.00, indicated by $\downarrow)$, in combination with a weaker axial signal attributable to the $\mathrm{H}_{\mathrm{ox}}-\mathrm{CO}$ state $(g=2.06,2.01$, indicated by $\nabla$ ) of the enzyme. This observation verifies the integrity of the enzyme in the presence of AspCDs and indicates that the enzyme was poised in its oxidized state, albeit a small population of the EPR silent $\mathrm{H}_{\text {red }}$ cannot be fully excluded. Notably, in samples frozen after exposure to light, the EPR signals from both $\mathrm{H}_{\mathrm{ox}}$ and $\mathrm{H}_{\mathrm{ox}}-\mathrm{CO}$ were lost (Figure $3 \mathrm{~b}$, red line), indicating accumulation of the $\mathrm{H}_{\text {red }}$ state in the photocatalytic system.

Visualization of the Interaction within the Biohybrid Assembly. The close interaction of AspCDs and CrHydAl was demonstrated by native acrylamide gel electrophoresis, and the corresponding gel image is shown in Figure 5. In

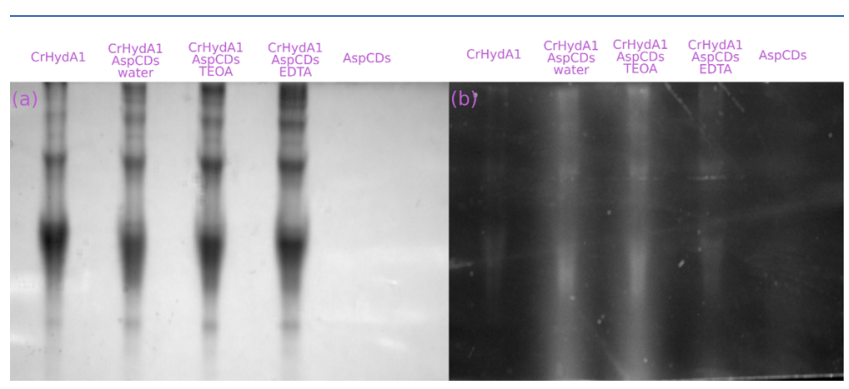

Figure 5. (a) Native $12 \%$ PAGE of CrHydAl with AspCDs preincubated in different environments (water, 10\% TEOA, and 0.1 M EDTA) stained with brilliant blue and (b) under $360 \mathrm{~nm}$ UV light. The free AspCDs migrate with the front of the gel with bromophenol blue.

isolation, the AspCDs migrated with the front of the gel and were not discernible. However, when the particles were incubated with CrHydA1, small fractions of the particles were located on the position of the CrHydAl bands, as is visible from the gel under UV illumination. The fluorescent bands were clearly visible for the interaction of AspCDs and CrHydAl in the absence of the electron donor and in the TEOA solution. Conversely, incubation in the presence of EDTA resulted in weakening of the fluorescence. It should also be noted that sodium dodecyl sulfate-polyacrylamide gel electrophoresis (SDS-PAGE) exhibited only a single protein band (Figure S8), while additional bands of CrHydA1 were clearly observable following the native polyacrylamide gel electrophoresis (PAGE) separation. Therefore, while the enzyme is pure, there appears to be a certain degree of inhomogeneity of the enzyme population under these conditions. The localization of AspCDs in the bands of CrHydA1 clearly visualizes the close interaction and influence of the sacrificial electron donor on the formation of the photoactive AspCDs/CrHydA1 complex. Notably, from electrophoresis, it can be observed that there is still a strong attraction between $\mathrm{CDs}$ and $\mathrm{CrHydAl}$ in the absence of any sacrificial donor. The result is particularly encouraging as this half-reaction system can be considered for a full water-splitting system that only uses water as a proton and electron source.

Photocatalytic Hydrogen Evolution. Having spectroscopically verified the photodriven reduction of the enzyme, we studied the photocatalytic performance of the AspCDs/ CrHydAl assembly systems employing EDTA or TEOA as the electron donor at $\mathrm{pH} 7$ (Figure 6). The impact of the redox mediator (methyl viologen) on the photocatalytic performance and stability was investigated. ${ }^{50}$ In order to prevent the inhibition of the $[\mathrm{FeFe}]$ hydrogenase by $\mathrm{UV}$ light, ${ }^{51}$ the photoactivity measurements were performed under white lightemitting diode (LED) illumination $\left(50 \mathrm{~mW} \mathrm{~cm}^{-2}, 420-700\right.$ $\mathrm{nm}){ }^{44}$

Both in the presence and absence of the redox mediator $\left(\mathrm{MV}^{2+}\right), \mathrm{H}_{2}$ production was observed for the biohybrid AspCDs/CrHydA1 assemblies employing various sacrificial electron donors. In the system with EDTA, the amount of evolved hydrogen during the first hour of light irradiation was $0.14 \pm 0.05 \mu \mathrm{mol} \mathrm{H}_{2}$ and increased by a factor of 6 in the presence of $\mathrm{MV}^{2+}\left(0.77 \pm 0.08 \mu \mathrm{mol} \mathrm{H}_{2}\right)$. This observation indicates that the electrostatic interaction between AspCDs and CrHydAl in EDTA is not efficient for direct electron transfer to the enzyme. On the other hand, the measurement in TEOA showed higher $\mathrm{H}_{2}$ evolution without $\mathrm{MV}^{2+}(0.62 \pm$ $0.11 \mu \mathrm{mol})$ than the system with $\mathrm{MV}^{2+}(0.33 \pm 0.09 \mu \mathrm{mol})$ during the first hour of illumination (Figure 6a). To the best of our knowledge, this is the first example of a carbon-based nanomaterial where hydrogen evolution in the absence of a redox mediator matches the efficiency of mediated systems. These findings reveal that the negatively charged AspCD particles interact stronger with the positively charged active site of CrHydAl in solutions containing TEOA, as compared to the EDTA system. As the $\mathrm{pH}$ is identical in the two biohybrid systems, the difference in photocatalytic behavior is attributed to the nature of the sacrificial electron donors. On one hand, the negatively charged EDTA (mostly present in the $\mathrm{HY}_{3}{ }^{-}$ form at $\left.\mathrm{pH} 7, \mathrm{pK}_{5}=6.13\right)^{52}$ can interact with the positive surface pocket of $\mathrm{CrHydA1}$ (Figure $4 \mathrm{a}, \mathrm{b}$ ) and thus prevent the electrostatic attraction between the $\mathrm{CD}$ particles and the enzyme (Figure 4c). On the other hand, TEOA should not be deprotonated at $\mathrm{pH} 7\left(\mathrm{p} K_{\mathrm{a}}=7.7\right)^{53}$ and therefore should not
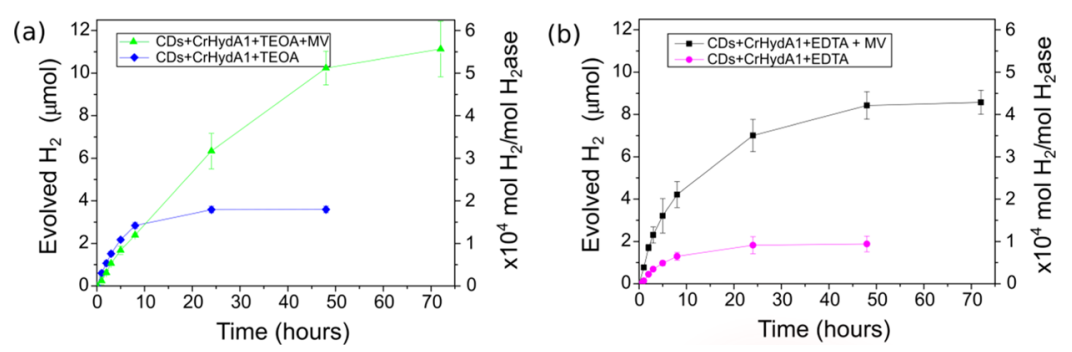

Figure 6. (a) Evolved hydrogen initiated by light irradiation of AspCDs $\left(0.5 \mathrm{mg} \mathrm{mL}^{-1}, 2 \mathrm{~mL}\right.$ in total) with $250 \mathrm{pmol}$ of $\mathrm{CrHydA} 1$ at $\mathrm{pH} 7 \mathrm{with}$ and without methyl viologen $(10 \mu \mathrm{mol})$ in the presence of TEOA and (b) hydrogen evolution in the presence of EDTA with and without MV; the systems missing one key component (AspCDs, CrHydA1, or the sacrificial electron donor) or kept in darkness did not evolve any hydrogen. 

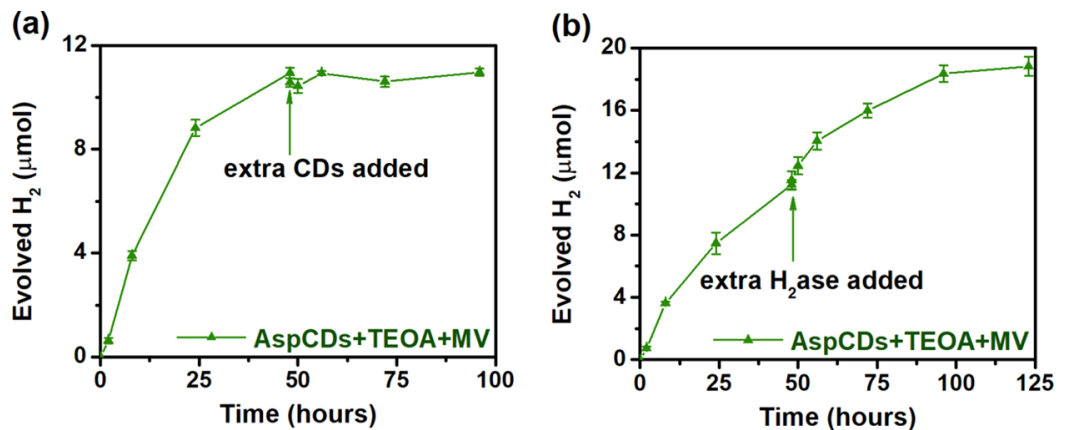

Figure 7. Addition of extra quantities of (a) AspCDs $(0.5 \mathrm{mg})$ or (b) CrHydA1 (250 pmol) in TEOA with methyl viologen.

disrupt the electrostatic interaction between AspCDs and CrHydA1.

External quantum efficiency (EQE) was evaluated for the system without the redox mediator in TEOA. The EQE measured at $420 \mathrm{~nm}$ during the first hour was $1.7 \%$, which is 4 times higher than the EQE of CDs with the $[\mathrm{NiFe}(\mathrm{Se})]$ hydrogenase illuminated at $360 \mathrm{~nm}^{42}$ In the presence of 100 pmol of CrHydA1, $1.73 \mu \mathrm{mol}\left(\mathrm{H}_{2}\right) \mathrm{mg}^{-1}$ (hydrogenase) $\mathrm{min}^{-1}$ was produced (Figure S9). A table comparing the performance of the AspCDs/CrHydAl assembly with that of the related state-of-the-art systems is presented in the Supporting Information (Table S2). ${ }^{6-9,18,25-31,41,54}$

Extended catalytic assays revealed that all combinations of electron donors (TEOA or EDTA) and the redox mediator (with or without $\mathrm{MV}^{2+}$ ) produced $\mathrm{H}_{2}$ continuously during the first $8 \mathrm{~h}$, at which time the hydrogen accumulation plateaued for systems without $\mathrm{MV}^{2+}$ (Figure 6). Addition of either extra AspCDs or CrHydAl did not restart hydrogen evolution (Figure S10), showing that both AspCDs and CrHydA1 were deactivated upon extended operation. In contrast, employing a redox mediator $\left(\mathrm{MV}^{2+}\right)$ prolonged the stability of the photocatalytic system, enabling almost linear hydrogen gas production during $48 \mathrm{~h}$ in TEOA (Figure 6a). In this case, the decrease in the $\mathrm{H}_{2}$ production was not due to the instability of the AspCDs but rather reflected the stability of the enzyme. The addition of fresh AspCDs to the system with $\mathrm{MV}^{2+}$ when hydrogen production had ceased had a negligible effect on the system (Figure 7a). Conversely, hydrogen production could be restarted by the addition of a new aliquot of CrHydAl (Figure $7 \mathrm{~b})$. In contrast to the performance of the biohybrid assembly in TEOA, in the presence of EDTA, the overall activity started to decrease after $24 \mathrm{~h}$ of light irradiation (both with and without $\mathrm{MV}^{2+}$, Figure $6 \mathrm{~b}$ ), attributed to enzyme inhibition through iron chelation. ${ }^{55}$

To understand if the performance of the system was limited by the photon flux, we performed additional experiments, where two neutral density filters (60\% transmittance and 30\% transmittance) were applied in front of the LED lamp. Similar initial hydrogen evolution reactions (HERs) were observed for the systems AspCDs/CrHydAl/TEOA and AspCDs/CrHy$\mathrm{dAl} / \mathrm{MV} / \mathrm{TEOA}$ without and with the $60 \%$ transmittance filter. These findings indicate that the performance of the AspCDs/CrHydA1 assembly was not limited by the light intensity (Figure S11 and Table S3). More specifically, during the first $48 \mathrm{~h}$ of illumination under $60 \mathrm{~T} \%$ irradiation, minor deviations (within the error) were observed for both systems with and without methyl viologen (Figure S11). After $48 \mathrm{~h}$, the AspCDs/CrHydA1/MV/TEOA system illuminated without the neutral density filter reached its plateau (Figure S11b), while under $60 \mathrm{~T} \%$ illumination, hydrogen continued to evolve for an additional $120 \mathrm{~h}$, generating extra $5 \pm 1 \mu \mathrm{mol}$ of $\mathrm{H}_{2}$. Thus, in the latter case, the stability of the biohybrid assembly extended beyond 1 week. We attribute the increase in hydrogen evolution to the enhanced stability of the hydrogenase under reduced light intensity illumination based on the previous observation that hydrogen evolution could be restarted after $48 \mathrm{~h}$ of illumination without a filter by the addition of fresh hydrogenase (Figure $7 b$ ). A further decrease of the photon flux (30 T\% LED light), however, decreased the hydrogen gas production by $\sim 40 \%$ (Table S3).

\section{DISCUSSION}

The difference in the photocatalytic behavior between the systems with and without methyl viologen shows that $\mathrm{MV}^{2+}$ / $\mathrm{MV}^{\bullet+}$ not only acts as a redox mediator but also greatly enhances the stability of the system. It suggests that during extended illumination, the direct charge transfer from AspCDs to CrHydAl becomes insufficient for overcoming the selfdecomposition of AspCDs, and the decomposed AspCDs can subsequently deactivate $\mathrm{CrHydA} 1$. The addition of $\mathrm{MV}^{2+}$ provides a reservoir of a suitable electron acceptor for the photoreduced AspCD, thereby preventing photodegradation and extending its performance beyond 1 week.

In order to further understand the effect of the interaction between $\mathrm{CDs}$ and the hydrogenase on electron-transfer processes in the systems, we determined reaction rates of the $\mathrm{CD}$ reduction by electron donors upon light illumination (eq 1, $\left.\nu_{1}\right)$, the reduction of $\mathrm{CrHydA1}$ by the reduced CDs without (eq 2, $\nu_{2}$ ) and with (eq 3, $\left.\nu_{3}\right) \mathrm{MV}^{2+}$, and the reduction of CrHydAl by both $\mathrm{MV}^{\bullet+}$ and $\mathrm{CD}^{\bullet-}$ (eq 4, $\nu_{4}$ ) in the presence of different electron donors (subscript $\mathrm{T}$ for TEOA and $\mathrm{E}$ for EDTA in the rate symbols). The corresponding reaction rates are collected in Table 1.

$$
\begin{aligned}
& \text { El. donor }+\mathrm{CD}+h \nu \rightarrow \mathrm{CD}^{\bullet-}+\text { El. donor }{ }^{+} \\
& \mathrm{d}\left[\mathrm{CD}^{\bullet-}\right] / \mathrm{d} t=\nu_{1}
\end{aligned}
$$

Without $\mathrm{MV}^{2+}$

$$
\begin{aligned}
\mathrm{CD}^{\bullet-}+\mathrm{CrHydAl} & \rightarrow \mathrm{CD}+\mathrm{CrHydAl}^{-} \\
\mathrm{d}\left[\mathrm{CrHydAl}^{-}\right] / \mathrm{d} t & =\nu_{2}
\end{aligned}
$$

With $\mathrm{MV}^{2+}$

$$
\mathrm{CD}^{\bullet-}+\mathrm{MV}^{2+} \rightarrow \mathrm{CD}+\mathrm{MV}^{\bullet+} \quad \mathrm{d}\left[\mathrm{MV}^{\bullet+}\right] / \mathrm{d} t=\nu_{3}
$$


Table 1. Rate Values for the Biohybrid AspCDs/CrHydA1 System in TEOA and EDTA ${ }^{a}$

\begin{tabular}{cccc} 
& \multicolumn{3}{c}{$\mathrm{TEOA}^{b}$} \\
$\nu_{1 \mathrm{~T}}$ & $\nu_{2 \mathrm{~T}}\left(\mu \mathrm{mol} \mathrm{L}^{-1} \mathrm{~h}^{-1}\right)$ & $\nu_{3 \mathrm{~T}}\left(\mu \mathrm{mol} \mathrm{L}^{-1} \mathrm{~h}^{-1}\right)$ & $\nu_{4 \mathrm{~T}}\left(\mu \mathrm{mol} \mathrm{L}^{-1} \mathrm{~h}^{-1}\right)$ \\
n.d & $458 \pm 5$ & $1708 \pm 195$ & $418 \pm 17$ \\
& & $\mathrm{EDTA}^{b}$ & \\
$\nu_{1 \mathrm{E}}$ & $\nu_{2 \mathrm{E}}\left(\mu \mathrm{mol} \mathrm{L}^{-1} \mathrm{~h}^{-1}\right)$ & $\nu_{3 \mathrm{E}}\left(\mu \mathrm{mol} \mathrm{L}^{-1} \mathrm{~h}^{-1}\right)$ & $\nu_{4 \mathrm{E}}\left(\mu \mathrm{mol} \mathrm{L}^{-1} \mathrm{~h}^{-1}\right)$ \\
n.d & $265 \pm 27$ & $1796 \pm 157$ & $862 \pm 92$
\end{tabular}

${ }^{a} \nu_{3}$ values are determined as an amount of produced $\mathrm{MV}^{\bullet+}$ in the initial $5 \mathrm{~min}$ of light irradiation (an extinction coefficient of 13,700 $\mathrm{M}^{-1} \mathrm{~cm}^{-1}$ at $605 \mathrm{~nm}^{56}$ ). The $\nu_{2}$ and $\nu_{4}$ values are determined from the amount of evolved hydrogen (two-electron process) in the initial $3 \mathrm{~h}$ of light irradiation, with a light intensity of $50 \mathrm{~mW} \mathrm{~cm}^{-2}(420-$ $700 \mathrm{~nm}$, white LED light). ${ }^{b}$ Identical concentration of AspCDs (0.5 $\left.\mathrm{mg} \mathrm{mL} \mathrm{m}^{-1}\right)$ and $\mathrm{MV}(5 \mathrm{mM})$ was used for determination of the given rate values; the time scale $\left(3 \mathrm{~h}\right.$ for $\mathrm{H}_{2}$ evolution and $5 \mathrm{~min}$ for $\mathrm{MV}^{\bullet+}$ evolution) is selected according to the initial linearity of the photoreaction. $\nu_{4}$ is calculated from hydrogen evolution with an assumption that all reduced hydrogenases are used for hydrogen production.

$$
\begin{gathered}
x \mathrm{MV}^{\bullet+}+y \mathrm{CD}^{\bullet-}+(x+y) \mathrm{CrHydAl} \rightarrow x \mathrm{MV}^{2+}+y \mathrm{CD} \\
+(x+y) \mathrm{CrHydAl}^{-} \quad \mathrm{d}\left[\mathrm{CrHydAl}^{-}\right] / \mathrm{d} t=\nu_{4}
\end{gathered}
$$

For the TEOA-based system, because the AspCDs have been proved to be deactivated/decomposed within $8-10 \mathrm{~h}$ in the TEOA-based system without $\mathrm{MV}^{2+}$ (Figure S12), the rate of the generation of reduced carbon dots, $\mathrm{CD}^{\bullet-}\left(\nu_{1 \mathrm{~T}}\right.$, assuming one $\mathrm{CD}$ gets one electron), must be much faster than the rate of the following step reducing CrHydA1 $\left(\nu_{2 \mathrm{~T}}, 458 \mu \mathrm{mol} \mathrm{L}{ }^{-1}\right.$ $\mathrm{h}^{-1}$ ), which actually is proved by the experiment with addition of $\mathrm{MV}^{2+}$. The much faster $\nu_{3 \mathrm{~T}}$ indicates that the formation of $\mathrm{CD}^{\bullet-}$ should be faster or at least equal to $1708 \mu \mathrm{mol} \mathrm{L} \mathrm{L}^{-1} \mathrm{~h}^{-1}$. Therefore, $\nu_{2 \mathrm{~T}}$ is the rate-determining step in the system to generate reduced $\mathrm{CrHydAl}$ (coded as $\mathrm{CrHydA1}^{-}$) in the absence of $\mathrm{MV}^{2+}$.

In the presence of $\mathrm{MV}^{2+}$, as $\mathrm{MV}^{2+}$ can oxidize $\mathrm{CD}^{\bullet-}$ more efficiently than CrHydA1 does, $\nu_{3 \mathrm{~T}}\left(1708 \mu \mathrm{mol} \mathrm{L} \mathrm{L}^{-1} \mathrm{~h}^{-1}\right) \gg$ $\nu_{2 \mathrm{~T}}\left(458 \mu \mathrm{mol} \mathrm{L} \mathrm{L}^{-1} \mathrm{~h}^{-1}\right)$. After the first run of the hydrogen evolution from the system in the presence of $\mathrm{MV}^{2+}(48 \mathrm{~h})$, we can still see that the reduced $\mathrm{MV}^{2+}\left(\mathrm{MV}^{\bullet+}\right)$ remains in the solution, indicating that the generation of $\mathrm{MV}^{\bullet+}$ is faster than consumption of $\mathrm{MV}^{\bullet+}$, which is also proved from the reaction rates, that is, $\nu_{3 \mathrm{~T}}\left(1708 \mu \mathrm{mol} \mathrm{L}^{-1} \mathrm{~h}^{-1}\right)>\nu_{4 \mathrm{~T}}\left(418 \mu \mathrm{mol} \mathrm{L} \mathrm{L}^{-1}\right.$ $\left.\mathrm{h}^{-1}\right)$. It means that the reduction of $\mathrm{MV}^{2+}$ by $\mathrm{CD}^{\bullet-}$ outcompetes other reactions. Interestingly, $\nu_{2 \mathrm{~T}}$ and $\nu_{4 \mathrm{~T}}$ have similar rates whether there is $\mathrm{MV}^{2+}$ or not, providing two possibilities: (a) the electron-transfer rate from $\mathrm{MV}^{\bullet+}$ to the hydrogenase is similar to that from $\mathrm{CD}^{\bullet-}$ to the hydrogenase and (b) the reduction of the hydrogenase is still dominated by the electron transfer from $\mathrm{CD}^{\bullet-}$. The former one can be easily ruled out by comparing both TEOA- and EDTA-based systems in the presence of $\mathrm{MV}^{2+}$. The formation of $\mathrm{MV}^{\bullet+}$ in both systems is almost equally fast, that is, $\nu_{3 \mathrm{~T}} \approx \nu_{3 \mathrm{E}}$. However, the EDTA-based system shows a much faster $\nu_{4 \mathrm{E}}\left(862 \mu \mathrm{mol} \mathrm{L}{ }^{-1}\right.$ $\left.\mathrm{h}^{-1}\right)$ than the TEOA-based system with a $\nu_{4 \mathrm{~T}}$ of $418 \mu \mathrm{mol} \mathrm{L}^{-1}$ $\mathrm{h}^{-1}$, which means that the electron transfer from $\mathrm{MV}^{\bullet+}$ to the hydrogenase must be faster than that from $\mathrm{CD}^{\bullet-}$. The result implies that the formation of $\mathrm{CrHydAl}^{-}$in the TEOA-based system in the presence of $\mathrm{MV}^{2+}$ is still dominated by electron transfer from $\mathrm{CD}^{\bullet-}$ to the hydrogenase, attributable to the strong interaction between CDs and the hydrogenase in the system. Therefore, the formation rate of $\mathrm{CrHydA1}^{-}, \nu_{4 \mathrm{~T}}$, is still the rate-determining step.

For the EDTA-based system, the situation is obviously distinguished from the TEOA system. In the absence of $\mathrm{MV}^{2+}$, the formation rate of $\mathrm{CrHydAl}^{-}, \nu_{2 \mathrm{E}}$, is much slower than that from the TEOA-based system because of the weaker interaction between CDs and the hydrogenase in the EDTAbased system (Figure 5). Therefore, the rate-determining step is still the electron transfer from $\mathrm{CD}^{\bullet-}$ to the hydrogenase. However, in the presence of $\mathrm{MV}^{2+}$, the reduction of $\mathrm{MV}^{2+}$ by $\mathrm{CD}^{\bullet-}$ is much faster than the reduction of the hydrogenase by $\mathrm{CD}^{\bullet-}$, that is, $\nu_{3 \mathrm{E}}\left(1796 \mu \mathrm{mol} \mathrm{L}{ }^{-1} \mathrm{~h}^{-1}\right)>\nu_{2 \mathrm{E}}\left(265 \mu \mathrm{mol} \mathrm{L}{ }^{-1}\right.$ $\left.\mathrm{h}^{-1}\right)$. As discussed above, one can see that the hydrogen evolution rate in the EDTA-based system, $\nu_{4 \mathrm{E}}\left(862 \mu \mathrm{mol} \mathrm{L}{ }^{-1}\right.$ $\left.\mathrm{h}^{-1}\right)$, is much faster than that in the TEOA-based system, $\nu_{4 \mathrm{~T}}$ $\left(418 \mu \mathrm{mol} \mathrm{L}^{-1} \mathrm{~h}^{-1}\right)$. The result suggests that the weaker interaction between CDs and the hydrogenase in the EDTAbased system actually facilitates the electron transfer from $\mathrm{MV}^{\bullet+}$ to the hydrogenase. It is probably because the unblocked hydrogenase surface gives more freedom to $\mathrm{MV}^{\bullet+}$ to interact with the active site. The formation rate of $\mathrm{CrHydAl}^{-}$is therefore dominated by $\mathrm{MV}^{\bullet+}$ rather than by $\mathrm{CD}^{\bullet-}$, which is different from the TEOA-based system. However, the formation rate of $\mathrm{MV}^{\bullet+}$ is still faster than the rate of consumption of $\mathrm{MV}^{\bullet+}$, that is, $\nu_{3 \mathrm{E}}\left(1796 \mu \mathrm{mol} \mathrm{L} \mathrm{L}^{-1} \mathrm{~h}^{-1}\right)>$ $\nu_{4 \mathrm{E}}\left(862 \mu \mathrm{mol} \mathrm{L} \mathrm{L}^{-1} \mathrm{~h}^{-1}\right)$. We can still see the accumulation of $\mathrm{MV}^{\bullet+}$ during the photocatalysis, indicating that the electron transfer from $\mathrm{MV}^{\bullet+}$ to the hydrogenase is the rate-determining step.

\section{CONCLUSIONS}

In conclusion, we prepared highly fluorescent carbon dots (AspCDs) by solvothermal carbonization of aspartic acid and used them as a photosensitizer in a self-assembled biohybrid system with CrHydAl as a hydrogen evolution catalyst. The AspCDs/CrHydA1 self-assembly is attributed to the complementary charge surface between AspCDs (negative) and the patch close to the active site of the enzyme (positive). The formation of the biohybrid complex between AspCDs and $\mathrm{CrHydAl}$ in water has been clearly observed from native gel electrophoresis. Oppositely charged sacrificial electron donors such as TEOA and EDTA have shown an antipodal effect on the stability of the biohybrid complex and therefore have influenced the photocatalytic performance. In brief, the positively charged TEOA allows the biohybrid complex AspCDs/CrHydA1 to retain the interaction between the positively charged binding pocket close to the hydrogenase active site and the negatively charged AspCDs, resulting in better photo-catalytic performance and a better charge-transfer rate as compared to the system operating in the presence of negatively charged EDTA. Moreover, this is the first time when efficient hydrogen evolution in the absence of a redox mediator was observed for carbon-based nanomaterials. Still, the presence of $\mathrm{MV}^{2+}$ has a significant effect on the stability, extending the operating lifetime of the biohybrid assembly to 1 week. This effect is attributed to the acceleration of regeneration of AspCDs by $\mathrm{MV}^{2+}$, preventing accumulation of electrons on the reduced AspCDs, as well as the enhanced stability of CrHydAl under continuous illumination (60 T\%). An EQE of $1.7 \%$ makes the AspCD/CrHydA1 system among the most efficient biofriendly photocatalytic systems using hydrogenase as the catalyst. In a wider context, the observed photocatalytic performance in combination with the long 
stability underscores the potential of this latest member of the carbon nanomaterial family.

\section{EXPERIMENTAL SECTION}

Materials and Methods. All chemicals were obtained from Sigma-Aldrich and used without further purification unless otherwise stated. Absolute ethanol (99.5\%+) was obtained from VWR Chemicals. Dialysis tubing ( $2 \mathrm{kDa}$ cutoff, benzoylated) for purification of particles was also obtained from Sigma-Aldrich. CrHydAl was prepared following literature protocols, ${ }^{57,58}$ and the specific activity of the used batch was $625 \mu \mathrm{mol}\left(\mathrm{H}_{2}\right) \mathrm{mg}^{-1}$ (hydrogenase) $\mathrm{min}^{-1}$.

Preparation and Characterization of CDs. CDs (AspCDs) were prepared by solvothermal decomposition of L-aspartic acid. In brief, $500 \mathrm{mg}$ of aspartic acid was redispersed in $15 \mathrm{~mL}$ of absolute ethanol in an ultrasound bath for $30 \mathrm{~min}$. The prepared suspension, even with the undissolved parts, was transferred into a reaction autoclave with a Teflon inset and kept at $210{ }^{\circ} \mathrm{C}$ for $8 \mathrm{~h}$ in an oven. The high reaction temperature led to the complete dissolution of the precursor and formation of highly fluorescent particles. The solution was filtered through a $200 \mathrm{~nm}$ Teflon syringe filter and transferred into $20 \mathrm{~mL}$ of deionized water. Afterward, the solution was heated at $40{ }^{\circ} \mathrm{C}$ in a reaction flask for several hours until the unwanted ethanol was removed. The obtained water solution of AspCDs was also passed through a syringe filter and dialyzed against ultrapure water for 1 day to remove unwanted low molecular contaminants. The concentration of the obtained stock solution of AspCDs was determined by drying the known aliquots.

Photoluminescence spectra were obtained on an FLS980 fluorescence spectrometer from Edinburgh Instruments Company equipped with a $450 \mathrm{~W}$ xenon arc lamp as the excitation source for steady-state experiments and with an EPL-375 ps pulsed diode laser. An absolute method was used for determination of the photoluminescence QY. Samples in the liquid phase were measured in a UV quartz cuvette (light path $=10 \mathrm{~mm}$ ). The same cuvette filled only with solvents was used as a reference. Three reference dyes with the determined PL QY were used to calibrate QY measurements in an integrated sphere: 2-aminopyridine (a reference QY of $84 \%$, Aldrich), Rhodamine 101 (a reference QY of 100\%, exciton), and 4-(dicyanomethylene)-2-methyl-6-(4-dimethylaminostyryl)- $4 H$-pyran in dimethyl sulfoxide (a reference QY of $57 \%$, Aldrich). TEM images were measured using a JEOL 2010 transmission electron microscope operating at $160 \mathrm{kV}$. The high-resolution TEM images were obtained using an FEI Titan electron microscope operating at $80 \mathrm{kV}$. The log-normal distribution of the particles was determined by manual particle counting using the ImageJ software. XPS was performed on a PHI VersaProbe II (Physical Electronics) spectrometer using an $\mathrm{Al} \mathrm{K} \alpha$ source $(15 \mathrm{kV}, 50 \mathrm{~W})$. The data were fitted by the MultiPak (Ulvac-PHI, Inc.) software and referred to the $\mathrm{C} 1 \mathrm{~s}$ peak at $284.80 \mathrm{eV}$. The Fourier transform infrared (FT-IR) spectrum was obtained on an iS5 Thermo Nicolet FT-IR spectrometer using the Smart Orbit ZnSe ATR technique. The zeta potential of the particles was recorded at various $\mathrm{pH}$ values on a Zetasizer Nano Zs instrument (Malvern, UK). The NMR spectra in the presence and absence of TEOA before and after irradiation were recorded on a JEOL (400YH magnet) Resonance $400 \mathrm{MHz}$ spectrometer.

The generation of the reduced form of methyl viologen $\left(\mathrm{MV}^{\bullet+}\right)$ was measured in a sealed UV-vis cuvette. In brief, 1.5
$\mathrm{mL}$ of the stock AspCD solution $\left(0.4 \mathrm{mg} \mathrm{mL} \mathrm{m}^{-1}\right)$ was transferred into the cuvette and diluted with $1.5 \mathrm{~mL}$ of the stock solution of the sacrificial electron donor (0.2 M EDTA or $20 \%$ TEOA; the $\mathrm{pH}$ was changed by adding $1 \mathrm{M} \mathrm{NaOH}$ or $\mathrm{HCl}$ ). Subsequently, $30 \mu \mathrm{mol}$ of $10 \mathrm{mM}$ MV solution in water was added. The $\mathrm{pH}$ of the solution was controlled; the cuvette was sealed; and the solution was bubbled with argon for 15 min. The bubbled solution was taken as a background correction. Afterward, the sample was irradiated with an LED PAR38 lamp ( $17 \mathrm{~W}, 5000 \mathrm{~K}, 420-700 \mathrm{~nm}, 50 \mathrm{~mW} \mathrm{~cm}{ }^{-2}$, Zenaro Lighting $\mathrm{GmbH}$; the spectrum of the used LED and the absorption and reflectance spectrum of AspCDs are given in Figure S4 in the Supporting Information), and the generation of reduced MV was monitored by UV-vis measurement using a PerkinElmer Lambda 750 spectrometer.

Hydrogen Evolution. The hydrogen evolution was measured in $9 \mathrm{~mL}$ gastight headspace vials. The appropriate amount of hydrogenase was added to $2 \mathrm{~mL}$ of the oxygen-free AspCD solution in the sacrificial electron donor $\left(0.5 \mathrm{mg} \mathrm{mL}^{-1}\right.$ AspCDs, $0.1 \mathrm{M}$ EDTA $\mathrm{pH} 7$ or $10 \%$ TEOA pH 7). The measurements in the presence of a redox mediator were performed with $0.1 \mathrm{mmol}$ of methyl viologen ( $5 \mathrm{mM}$ solution). All of these operations were performed in an MBRAUN glovebox with a humid Ar atmosphere. After the start of the LED irradiation, every given hour, $100 \mu \mathrm{L}$ of the headspace was removed using a gastight Hamilton syringe. To avoid any oxygen pollution, the Hamilton needle and the top of the vial septa were covered with Play-Doh clay before the needle was removed. The tiny hole after the needle was immediately covered with clay. The amount of hydrogen evolved from the system was subsequently analyzed by gas chromatography (GC; PerkinElmer LLC, MA, USAC; PerkinElmer LLC, MA, USA). The experiments were performed three times, and the results are given as average values with standard deviations. The EQE at $420 \mathrm{~nm}$ was measured in a $3.5 \mathrm{~mL}$ gastight quartz cuvette with $2 \mathrm{~mL}$ of the solution and $1.5 \mathrm{~mL}$ of the headspace. The experimental setup of this measurement can be found in our previous work.

The structural view of the hydrogenase CrHydA1 (PDB ID: 3LX4) used in Figure 4 was provided by visualization of electrostatics provided by PyMOL (the PyMOL Molecular Graphics System, Version 2.2 Schrödinger, LLC.). Channels starting from iron/sulfur cluster positions and their size were calculated using MOLEonline. $^{59}$

Gel Electrophoresis. Native PAGE was performed according to the standard protocol. The $\mathrm{pH}$ value of the TRIS buffer used for preparation of the $12 \%$ gel was decreased to 7.0, and the applied voltage was kept at $50 \mathrm{~V}$. The gel was imaged using a Fusion FX5 with a $365 \mathrm{~nm}$ UV light source. The concentration of AspCDs in the $15 \mu \mathrm{L}$ applied on the wells was $0.5 \mathrm{mg} \mathrm{mL}^{-1}$; the amount of CrHydAl was 500 pmol.

EPR Spectroscopy. All EPR spectra were recorded on a Bruker EMX-micro spectrometer equipped with an EMXPremium bridge and an ER4119HS resonator. All samples were air-removed and kept in sealed bottles at room temperature except for the $\mathrm{CrHydAl}$ samples, which were stored at $77 \mathrm{~K}$ before mixing. A flat cell (a sample volume of $150 \mu \mathrm{L}$ ) was used for room-temperature EPR examination. Samples containing CrHydAl were mixed in a glovebox under an argon atmosphere and dim light before they were frozen to $77 \mathrm{~K}$ prior to low-temperature measurements. After the dark spectrum was recorded, each of these samples was first thawed 
slowly inside the glovebox before being exposed to light (white, $800 \mathrm{~W}$ ) for varied times $(1-4 \mathrm{~h}$ ). After illumination, the samples were frozen and stored in a liquid nitrogen bath $(77 \mathrm{~K})$ for subsequent examination. Illumination of such a sample outside the glovebox resulted in enzyme degradation, which was indicated by the detection of a $g=4.3$ signal (not shown, but see the text and Figure S7b). Illumination of other samples was carried out in situ under ambient conditions. EPR settings: RT measurements; microwave frequency $9.767 \mathrm{GHz}$, microwave power $0.5 \mathrm{~mW}$, modulation frequency $100 \mathrm{MHz}$, modulation amplitude $5 \mathrm{G}$, and time constant $40 \mathrm{~ms} ; \mathrm{T}=21$ $\mathrm{K}$, microwave frequency $9.385 \mathrm{GHz}$, microwave power $2 \mathrm{~mW}$, modulation frequency $100 \mathrm{MHz}$, modulation amplitude $8 \mathrm{G}$, and time constant $40 \mathrm{~ms}$.

\section{ASSOCIATED CONTENT}

\section{SI Supporting Information}

The Supporting Information is available free of charge at https://pubs.acs.org/doi/10.1021/acscatal.0c02474.

Detailed material characterization of the prepared AspCDs (zeta potential, FT-IR, high-resolution N 1s spectra, UV-vis absorption, and HRTEM), NMR study of the decomposition of AspCDs, effect of light intensities on photocatalytic performance, and additional explanation of the photoactivity in combination with further photoactivity measurements (PDF)

\section{AUTHOR INFORMATION}

\section{Corresponding Authors}

Gustav Berggren - Department of Chemistry-Ångström Laboratory, Molecular Biomimetic, Uppsala University, SE 751 20 Uppsala, Sweden; 이이.org/0000-0002-6717-6612; Email: gustav.berggren@kemi.uu.se

Haining Tian - Department of Chemistry-Ångström Laboratory, Physical Chemistry, Uppsala University, SE 75120 Uppsala, Sweden; 이 orcid.org/0000-0001-6897-2808; Email: haining.tian@kemi.uu.se

\section{Authors}

Kateřina Holá - Department of Chemistry-Ångström Laboratory, Physical Chemistry, Uppsala University, SE 75120 Uppsala, Sweden; Regional Centre of Advanced Technologies and Materials, Department of Physical Chemistry, Faculty of Science, Palacký University Olomouc, 78371 Olomouc, Czech Republic

Mariia V. Pavliuk - Department of Chemistry-Ångström Laboratory, Physical Chemistry, Uppsala University, SE 75120 Uppsala, Sweden

Brigitta Németh - Department of Chemistry-Ångström Laboratory, Molecular Biomimetic, Uppsala University, SE 751 20 Uppsala, Sweden

Ping Huang - Department of Chemistry—Ånström Laboratory, Molecular Biomimetic, Uppsala University, SE 751 20 Uppsala, Sweden

Lukáš Zdražil - Regional Centre of Advanced Technologies and Materials, Department of Physical Chemistry, Faculty of Science, Palacký University Olomouc, 78371 Olomouc, Czech Republic

Henrik Land - Department of Chemistry-Ångström

Laboratory, Molecular Biomimetic, Uppsala University, SE 751

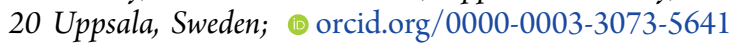

Complete contact information is available at:

https://pubs.acs.org/10.1021/acscatal.0c02474

\section{Author Contributions}

"K.H. and M.V.P. contributed equally.

\section{Notes}

The authors declare no competing financial interest.

\section{ACKNOWLEDGMENTS}

This work was supported by the Swedish Energy Agency (44641-1). K.H. and L.Z. would also like to acknowledge the support from the Student Project IGA_PrF_2020_022 of Palacky University Olomouc and the support from the ERDF project "Development of pre-applied research in nanotechnology and biotechnology" (no. CZ.02.1.01/0.0/0.0/ 17_048/0007323).

\section{REFERENCES}

(1) Wang, F.; Wang, W.-G.; Wang, H.-Y.; Si, G.; Tung, C.-H.; Wu, L.-Z. Artificial Photosynthetic Systems Based on [FeFe]-Hydrogenase Mimics: The Road to High Efficiency for Light-Driven Hydrogen Evolution. ACS Catal. 2012, 2, 407-416.

(2) Le Goff, A.; Artero, V.; Jousselme, B.; Tran, P. D.; Guillet, N.; Métayé, R.; Fihri, A.; Palacin, S.; Fontecave, M. From Hydrogenases to Noble Metal-Free Catalytic Nanomaterials for $\mathrm{H}_{2}$ Production and Uptake. Science 2009, 326, 1384-1387.

(3) Janssen, P. J. D.; Lambreva, M. D.; Plumeré, N.; Bartolucci, C.; Antonacci, A.; Buonasera, K.; Frese, R. N.; Scognamiglio, V.; Rea, G. Photosynthesis at the Forefront of a Sustainable Life. Front. Chem. 2014, 2, 36.

(4) Hammarström, L. Accumulative Charge Separation for Solar Fuels Production: Coupling Light-Induced Single Electron Transfer to Multielectron Catalysis. Acc. Chem. Res. 2015, 48, 840-850.

(5) Batzill, M. Fundamental Aspects of Surface Engineering of Transition Metal Oxide Photocatalysts. Energy Environ. Sci. 2011, 4, $3275-3286$.

(6) Reisner, E.; Fontecilla-Camps, J. C.; Armstrong, F. A. Catalytic Electrochemistry of a $[\mathrm{NiFeSe}]-H y d r o g e n a s e$ on $\mathrm{TiO} 2$ and Demonstration of Its Suitability for Visible-Light Driven H2 Production. Chem. Commun. 2009, 550-552.

(7) Polliotto, V.; Morra, S.; Livraghi, S.; Valetti, F.; Gilardi, G.; Giamello, E. Electron Transfer and H2 Evolution in Hybrid Systems Based on [FeFe]-Hydrogenase Anchored on Modified TiO2. Int. J. Hydrogen Energy 2016, 41, 10547-10556.

(8) Brown, K. A.; Dayal, S.; Ai, X.; Rumbles, G.; King, P. W. Controlled Assembly of Hydrogenase-CdTe Nanocrystal Hybrids for Solar Hydrogen Production. J. Am. Chem. Soc. 2010, 132, 9672-9680.

(9) Greene, B. L.; Joseph, C. A.; Maroney, M. J.; Dyer, R. B. Direct Evidence of Active-Site Reduction and Photodriven Catalysis in Sensitized Hydrogenase Assemblies. J. Am. Chem. Soc. 2012, 134, 11108-11111.

(10) Li, X.-B.; Tung, C.-H.; Wu, L.-Z. Quantum Dot Assembly for Light-Driven Multielectron Redox Reactions, Such as Hydrogen Evolution and $\mathrm{CO}_{2}$ Reduction. Angew. Chem., Int. Ed. 2019, 58, 10804-10811.

(11) Hou, W.; Cronin, S. B. A Review of Surface Plasmon Resonance-Enhanced Photocatalysis. Adv. Funct. Mater. 2013, 23, $1612-1619$.

(12) Cecconi, B.; Manfredi, N.; Montini, T.; Fornasiero, P.; Abbotto, A. Dye-Sensitized Solar Hydrogen Production: The Emerging Role of Metal-Free Organic Sensitizers. Eur. J. Org. Chem. 2016, 2016, 5194-5215.

(13) Wang, L.; Fernández-Terán, R.; Zhang, L.; Fernandes, D. L. A.; Tian, L.; Chen, H.; Tian, H. Organic Polymer Dots as Photocatalysts for Visible Light-Driven Hydrogen Generation. Angew. Chem., Int. Ed. 2016, 55, 12306-12310.

(14) Pati, P. B.; Damas, G.; Tian, L.; Fernandes, D. L. A.; Zhang, L.; Pehlivan, I. B.; Edvinsson, T.; Araujo, C. M.; Tian, H. An Experimental and Theoretical Study of an Efficient Polymer Nano- 
Photocatalyst for Hydrogen Evolution. Energy Environ. Sci. 2017, 10, 1372-1376.

(15) Liu, A.; Tai, C.-W.; Holá, K.; Tian, H. Hollow Polymer Dots: Nature-Mimicking Architecture for Efficient Photocatalytic Hydrogen Evolution Reaction. J. Mater. Chem. A 2019, 7, 4797-4803.

(16) Sprick, R. S.; Bai, Y.; Guilbert, A. A. Y.; Zbiri, M.; Aitchison, C. M.; Wilbraham, L.; Yan, Y.; Woods, D. J.; Zwijnenburg, M. A.; Cooper, A. I. Photocatalytic Hydrogen Evolution from Water Using Fluorene and Dibenzothiophene Sulfone-Conjugated Microporous and Linear Polymers. Chem. Mater. 2019, 31, 305-313.

(17) Yi, H.; Huang, D.; Qin, L.; Zeng, G.; Lai, C.; Cheng, M.; Ye, S.; Song, B.; Ren, X.; Guo, X. Selective Prepared Carbon Nanomaterials for Advanced Photocatalytic Application in Environmental Pollutant Treatment and Hydrogen Production. Appl. Catal., B 2018, 239, 408-424.

(18) Caputo, C. A.; Gross, M. A.; Lau, V. W.; Cavazza, C.; Lotsch, B. V.; Reisner, E. Photocatalytic Hydrogen Production Using Polymeric Carbon Nitride with a Hydrogenase and a Bioinspired Synthetic Ni Catalyst. Angew. Chem., Int. Ed. 2014, 53, 11538-11542.

(19) Ong, W.-J.; Tan, L.-L.; Ng, Y. H.; Yong, S.-T.; Chai, S.-P. Graphitic Carbon Nitride (g-C3N4)-Based Photocatalysts for Artificial Photosynthesis and Environmental Remediation: Are We a Step Closer to Achieving Sustainability? Chem. Rev. 2016, 116, 71597329.

(20) Hutton, G. A. M.; Martindale, B. C. M.; Reisner, E. Carbon Dots as Photosensitisers for Solar-Driven Catalysis. Chem. Soc. Rev. 2017, 46, 6111-6123.

(21) Baker, S. N.; Baker, G. A. Luminescent Carbon Nanodots: Emergent Nanolights. Angew. Chem., Int. Ed. 2010, 49, 6726-6744.

(22) Hola, K.; Zhang, Y.; Wang, Y.; Giannelis, E. P.; Zboril, R.; Rogach, A. L. Carbon Dots - Emerging Light Emitters for Bioimaging, Cancer Therapy and Optoelectronics. Nano Today 2014, 9, 590-603.

(23) Wei, W.; Xu, C.; Wu, L.; Wang, J.; Ren, J.; Qu, X. NonEnzymatic-Browning-Reaction: A Versatile Route for Production of Nitrogen-Doped Carbon Dots with Tunable Multicolor Luminescent Display. Sci. Rep. 2014, 4, 3564.

(24) Ding, H.; Wei, J.-S.; Zhang, P.; Zhou, Z.-Y.; Gao, Q.-Y.; Xiong, H.-M. Solvent-Controlled Synthesis of Highly Luminescent Carbon Dots with a Wide Color Gamut and Narrowed Emission Peak Widths. Small 2018, 14, 1800612.

(25) Yeh, T.-F.; Teng, C.-Y.; Chen, S.-J.; Teng, H. Nitrogen-Doped Graphene Oxide Quantum Dots as Photocatalysts for Overall WaterSplitting under Visible Light Illumination. Adv. Mater. 2014, 26, 3297-3303.

(26) Yang, P.; Zhao, J.; Wang, J.; Cui, H.; Li, L.; Zhu, Z. Multifunctional Nitrogen-Doped Carbon Nanodots for Photoluminescence, Sensor, and Visible-Light-Induced H2 Production. ChemPhysChem 2015, 16, 3058-3063.

(27) Martindale, B. C. M.; Hutton, G. A. M.; Caputo, C. A.; Reisner, E. Solar Hydrogen Production Using Carbon Quantum Dots and a Molecular Nickel Catalyst. J. Am. Chem. Soc. 2015, 137, 6018-6025.

(28) Bhattacharyya, S.; Ehrat, F.; Urban, P.; Teves, R.; Wyrwich, R.; Döblinger, M.; Feldmann, J.; Urban, A. S.; Stolarczyk, J. K. Effect of Nitrogen Atom Positioning on the Trade-off between Emissive and Photocatalytic Properties of Carbon Dots. Nat. Commun. 2017, 8, 1401.

(29) Martindale, B. C. M.; Hutton, G. A. M.; Caputo, C. A.; Prantl, S.; Godin, R.; Durrant, J. R.; Reisner, E. Enhancing Light Absorption and Charge Transfer Efficiency in Carbon Dots through Graphitization and Core Nitrogen Doping. Angew. Chem., Int. Ed. 2017, 56, $6459-6463$.

(30) Xu, X.; Tang, W.; Zhou, Y.; Bao, Z.; Su, Y.; Hu, J.; Zeng, H. Steering Photoelectrons Excited in Carbon Dots into Platinum Cluster Catalyst for Solar-Driven Hydrogen Production. Adv. Sci. 2017, 4, 1700273.

(31) Yan, Y.; Chen, J.; Li, N.; Tian, J.; Li, K.; Jiang, J.; Liu, J.; Tian, Q.; Chen, P. Systematic Bandgap Engineering of Graphene Quantum Dots and Applications for Photocatalytic Water Splitting and CO2 Reduction. ACS Nano 2018, 12, 3523-3532.
(32) Land, H.; Senger, M.; Berggren, G.; Stripp, S. T. Current State of $[\mathrm{FeFe}]-H y d r o g e n a s e$ Research: Biodiversity and Spectroscopic Investigations. ACS Catal. 2020, 10, 7069-7086.

(33) Lubitz, W.; Ogata, H.; Rüdiger, O.; Reijerse, E. Hydrogenases. Chem. Rev. 2014, 114, 4081-4148.

(34) Esmieu, C.; Raleiras, P.; Berggren, G. From Protein Engineering to Artificial Enzymes-Biological and Biomimetic Approaches towards Sustainable Hydrogen Production. Sustainable Energy Fuels 2018, 2, 724-750.

(35) Schilter, D.; Camara, J. M.; Huynh, M. T.; Hammes-Schiffer, S.; Rauchfuss, T. B. Hydrogenase Enzymes and Their Synthetic Models: The Role of Metal Hydrides. Chem. Rev. 2016, 116, 8693-8749.

(36) Winkler, M.; Senger, M.; Duan, J.; Esselborn, J.; Wittkamp, F.; Hofmann, E.; Apfel, U. P.; Stripp, S. T.; Happe, T. Accumulating the Hydride State in the Catalytic Cycle of [FeFe]-Hydrogenases. Nat. Commun. 2017, 8, 16115.

(37) Silakov, A.; Wenk, B.; Reijerse, E.; Lubitz, W. 14N HYSCORE Investigation of the $\mathrm{H}$-Cluster of [FeFe] Hydrogenase: Evidence for a Nitrogen in the Dithiol Bridge. Phys. Chem. Chem. Phys. 2009, 11, 6592-6599.

(38) Morra, S.; Giraudo, A.; Di Nardo, G.; King, P. W.; Gilardi, G.; Valetti, F. Site Saturation Mutagenesis Demonstrates a Central Role for Cysteine 298 as Proton Donor to the Catalytic Site in CaHydA [FeFe]-Hydrogenase. PLoS One 2012, 7, No. e48400.

(39) King, P. W. Designing Interfaces of Hydrogenase-Nanomaterial Hybrids for Efficient Solar Conversion. Biochim. Biophys. Acta, Bioenerg. 2013, 1827, 949-957.

(40) Gentil, S.; Che Mansor, S. M.; Jamet, H.; Cosnier, S.; Cavazza, C.; Le Goff, A. Oriented Immobilization of [NiFeSe] Hydrogenases on Covalently and Noncovalently Functionalized Carbon Nanotubes for H2/Air Enzymatic Fuel Cells. ACS Catal. 2018, 8, 3957-3964.

(41) Brown, K. A.; Wilker, M. B.; Boehm, M.; Dukovic, G.; King, P. W. Characterization of Photochemical Processes for H2 Production by CdS Nanorod-[FeFe] Hydrogenase Complexes. J. Am. Chem. Soc. 2012, 134, 5627-5636.

(42) Hutton, G. A. M.; Reuillard, B.; Martindale, B. C. M.; Caputo, C. A.; Lockwood, C. W. J.; Butt, J. N.; Reisner, E. Carbon Dots as Versatile Photosensitizers for Solar-Driven Catalysis with Redox Enzymes. J. Am. Chem. Soc. 2016, 138, 16722-16730.

(43) Birrell, J. A.; Rüdiger, O.; Reijerse, E. J.; Lubitz, W. Semisynthetic Hydrogenases Propel Biological Energy Research into a New Era. Joule 2017, 1, 61-76.

(44) Xu, B.; Tian, L.; Etman, A. S.; Sun, J.; Tian, H. SolutionProcessed Nanoporous NiO-Dye-ZnO Photocathodes: Toward Efficient and Stable Solid-State p-Type Dye-Sensitized Solar Cells and Dye-Sensitized Photoelectrosynthesis Cells. Nano Energy 2019, $55,59-64$.

(45) Happe, T.; Naber, J. D. Isolation, Characterization and Nterminal Amino Acid Sequence of Hydrogenase from the Green Alga Chlamydomonas Reinhardtii. Eur. J. Biochem. 1993, 214, 475-481.

(46) Lau, V. W.-h.; Klose, D.; Kasap, H.; Podjaski, F.; Pignié, M.-C.; Reisner, E.; Jeschke, G.; Lotsch, B. V. Dark Photocatalysis: Storage of Solar Energy in Carbon Nitride for Time-Delayed Hydrogen Generation. Angew. Chem., Int. Ed. 2017, 56, 510-514.

(47) Mulder, D. W.; Boyd, E. S.; Sarma, R.; Lange, R. K.; Endrizzi, J. A.; Broderick, J. B.; Peters, J. W. Stepwise FeFe-Hydrogenase HCluster Assembly Revealed in the Structure of HydA $\Delta \mathrm{eFG}$. Nature 2010, 465, 248-251.

(48) Berggren, G.; Adamska, A.; Lambertz, C.; Simmons, T. R.; Esselborn, J.; Atta, M.; Gambarelli, S.; Mouesca, J.-M.; Reijerse, E.; Lubitz, W.; Happe, T.; Artero, V.; Fontecave, M. Biomimetic Assembly and Activation of [FeFe]-Hydrogenases. Nature 2013, 499, 66-69.

(49) Tian, L.; Németh, B.; Berggren, G.; Tian, H. Hydrogen Evolution by a Photoelectrochemical Cell Based on a Cu2O-ZnO[FeFe] Hydrogenase Electrode. J. Photochem. Photobiol., A 2018, 366, 27-33. 
(50) Greene, B. L.; Schut, G. J.; Adams, M. W. W.; Dyer, R. B. PreSteady-State Kinetics of Catalytic Intermediates of an $[\mathrm{FeFe}]$ Hydrogenase. ACS Catal. 2017, 7, 2145-2150.

(51) Sensi, M.; Baffert, C.; Fradale, L.; Gauquelin, C.; Soucaille, P.; Meynial-Salles, I.; Bottin, H.; De Gioia, L.; Bruschi, M.; Fourmond, V.; Léger, C.; Bertini, L. Photoinhibition of FeFe Hydrogenase. ACS Catal. 2017, 7, 7378-7387.

(52) Coleman, W. F. Molecular Models of EDTA and Other Chelating Agents. J. Chem. Educ. 2008, 85, 1296.

(53) Simond, M. R.; Ballerat-Busserolles, K.; Coulier, Y.; Rodier, L.; Coxam, J.-Y. Dissociation Constants of Protonated Amines in Water at Temperatures from $293.15 \mathrm{~K}$ to $343.15 \mathrm{~K}$. J. Solution Chem. 2012, $41,130-142$.

(54) Adam, D.; Bösche, L.; Castañeda-Losada, L.; Winkler, M.; Apfel, U.-P.; Happe, T. Sunlight-Dependent Hydrogen Production by Photosensitizer/Hydrogenase Systems. ChemSusChem 2017, 10, 894-902.

(55) Partridge, C. D. P.; Yates, M. G. Effect of Chelating Agents on Hydrogenase in Azotobacter Chroococcum. Evidence That Nickel Is Required for Hydrogenase Synthesis. Biochem. J. 1982, 204, 339-344.

(56) Watanabe, T.; Honda, K. Measurement of the Extinction Coefficient of the Methyl Viologen Cation Radical and the Efficiency of Its Formation by Semiconductor Photocatalysis. J. Phys. Chem. 1982, 86, 2617-2619.

(57) Mészáros, L. S.; Németh, B.; Esmieu, C.; Ceccaldi, P.; Berggren, G. In Vivo EPR Characterization of Semi-Synthetic [FeFe] Hydrogenases. Angew. Chem., Int. Ed. 2018, 57, 2596-2599.

(58) Mulder, D. W.; Ortillo, D. O.; Gardenghi, D. J.; Naumov, A. V.; Ruebush, S. S.; Szilagyi, R. K.; Huynh, B.; Broderick, J. B.; Peters, J. W. Activation of HydA $\Delta$ EFG Requires a Preformed [4Fe-4S] Cluster. Biochemistry 2009, 48, 6240-6248.

(59) Pravda, L.; Sehnal, D.; Toušek, D.; Navrátilová, V.; Bazgier, V.; Berka, K.; Svobodová Vařeková, R.; Koča, J.; Otyepka, M. MOLEonline: A Web-Based Tool for Analyzing Channels, Tunnels and Pores (2018 Update). Nucleic Acids Res. 2018, 46, W368-W373. 